TITLE:

\title{
Nucleosome Assembly Alters the Accessibility of the Antitumor Agent Duocarmycin B2 to Duplex DNA
}

\section{AUTHOR(S):}

Zou, Tingting; Kizaki, Seiichiro; Pandian, Ganesh N.; Sugiyama, Hiroshi

\section{CITATION:}

Zou, Tingting ... [et al]. Nucleosome Assembly Alters the Accessibility of the Antitumor Agent Duocarmycin B2 to Duplex DNA. Chemistry - A European Journal 2016, 22(26): 87568758

\section{ISSUE DATE:}

2016-06-20

URL:

http://hdl.handle.net/2433/230882

\section{RIGHT:}

This is the accepted version of the following article: [Tingting Zou, Seiichiro Kizaki, Ganesh N. Pandian, Hiroshi Sugiyama. Nucleosome Assembly Alters the Accessibility of the Antitumor Agent Duocarmycin B2 to Duplex DNA. ChemBioChem (2016), 22, 26, 8756-8758], which has been published in final form at

https://doi.org/10.1002/chem.201600950. This article may be used for non-commercial purposes in accordance with. Wiley Terms and Conditions for Self-Archiving.; The full-text file will be made open to the public on 15 June 2017 in accordance with publisher's 'Terms and Conditions for Self-Archiving'; This is not the published version. Please cite only the published version;; この論文は出版社版でありません。引用の際には出版社版をご確認ご利用ください。 


\title{
Nucleosome assembly alters the accessibility of the antitumor agent duocarmycin $B_{2}$ to duplex DNA
}

\author{
Tingting Zou ${ }^{a}$, Seiichiro Kizaki ${ }^{a}$, Ganesh N. Pandian ${ }^{b}$, Hiroshi Sugiyama ${ }^{a, b^{*}}$
}

\begin{abstract}
To evaluate the reactivity of antitumor agents in a nucleosome architecture, we conducted in vitro studies to assess the alkylation level of duocarmycin $B_{2}$ on nucleosomes with core and linker DNA using sequencing gel electrophoresis. Our results suggested that the alkylating efficiencies of duocarmycin $B_{2}$ were significantly decreased in core DNA and increased at the histone-free linker DNA sites when compared with naked DNA condition. Our finding that nucleosome assembly alters the accessibility of duocarmycin $B_{2}$ to duplex DNA could advance their design as antitumor agents.
\end{abstract}

Advancing anti-tumor agents is of significant importance, as effective chemotherapy of malignant tumors is one of the great challenges of modern medicine ${ }^{[1]}$. Conventional agents have been applied to many cancer therapies, and new anti-tumor agents having therapeutic potential are being discovered. Duocarmycin, first reported in $1988^{[2][3]}$ and their analogues have been beneficial in treating many types of tumor disease ${ }^{[1][4]}$ via covalent interaction with DNA minor groove adenine N3 alkylation site ${ }^{[5][6]}$. However, in eukaryotic cells, the assembly of DNA and histone proteins into nucleosomes (the basic repeating subunits of chromatin) packs over two meters of DNA into the confines of the nucleus ${ }^{[7]}$. In such a highly compact structure, whether antitumor agents exhibit similar or distinct accessibility to duplex DNA as in the naked condition is yet to be clarified.

A report about the accessible regions of nucleosome core particles (NCPs) to minor-groove-binding pyrrole-imidazole polyamides (PIPs) showed that PIPs fail to bind NCPs only at sites that are blocked by interactions with the histone octamer ${ }^{[8]}$. NCPs were also shown to be fully accessible to some minorgroove-alkylating agents, and both the selectivity and efficiency of DNA alkylation were suggested to be unaffected by NCP packaging ${ }^{[9]}$. Furthermore, the base pair unstacking arising from DNA stretch induce extreme minor groove kinking near the nucleosome center, which in turn generate a hot spot for intercalation facilitating the alkylation by a novel anticancer compound $^{[10]}$.

However, in the actual chromatin condition, each nucleosome

[a] T. Zou, S. Kizaki, Prof. H. Sugiyama

Department of Science, Graduate School of Science

Kyoto University

sakyo, Kyoto 606-8501, Japan

hs@kuchem.kyoto-u.ac.jp

[b] Dr. N. G. Pandian, Prof. H. Sugiyama

nstitute for Integrated Cell-Material Sciences (iCeMS)

Kyoto University

Yoshida Ushinomiya-cho,

Sakyo, Kyoto 606-8502, Japan encompass not only nucleosome 'core', but also linker DNA, and in most instances, a linker histone ${ }^{[11]}$. As the essential composition of nucleosome, linker DNA provide a binding region for linker histone and then regulate epigenetic transcription ${ }^{[12]}$. Cisplatin and analogues were demonstrated that the preferred site of DNA binding was in the linker region of the nucleosome ${ }^{[13]}$. Some researchers adopted DNA fragment from the Xenopus Zaeuis $5 \mathrm{~S}$ rRNA gene for nucleosome reconstitution. The results exhibited that marked inhibition of the DNA cleavage induced by bleomycin ( 5 fold) and neocarzinostatin ( 2.4 fold) in the central region of nucleosomal DNA. Also in melphalan, about 2 fold inhibition in alkylation at adenine $\mathrm{N}-3$ throughout the nucleosome was shown ${ }^{[14][15]}$.

Taken together, the previous reports suggest the existence of undiscovered nucleosome features that can be harnessed in advancing the cancer drug discovery. Accordingly, 382 bp DNA containing Widom 601 nucleosome positioning sequence and duocarmycin $\mathrm{B}_{2}$ were adopted for the nucleosome reconstitution

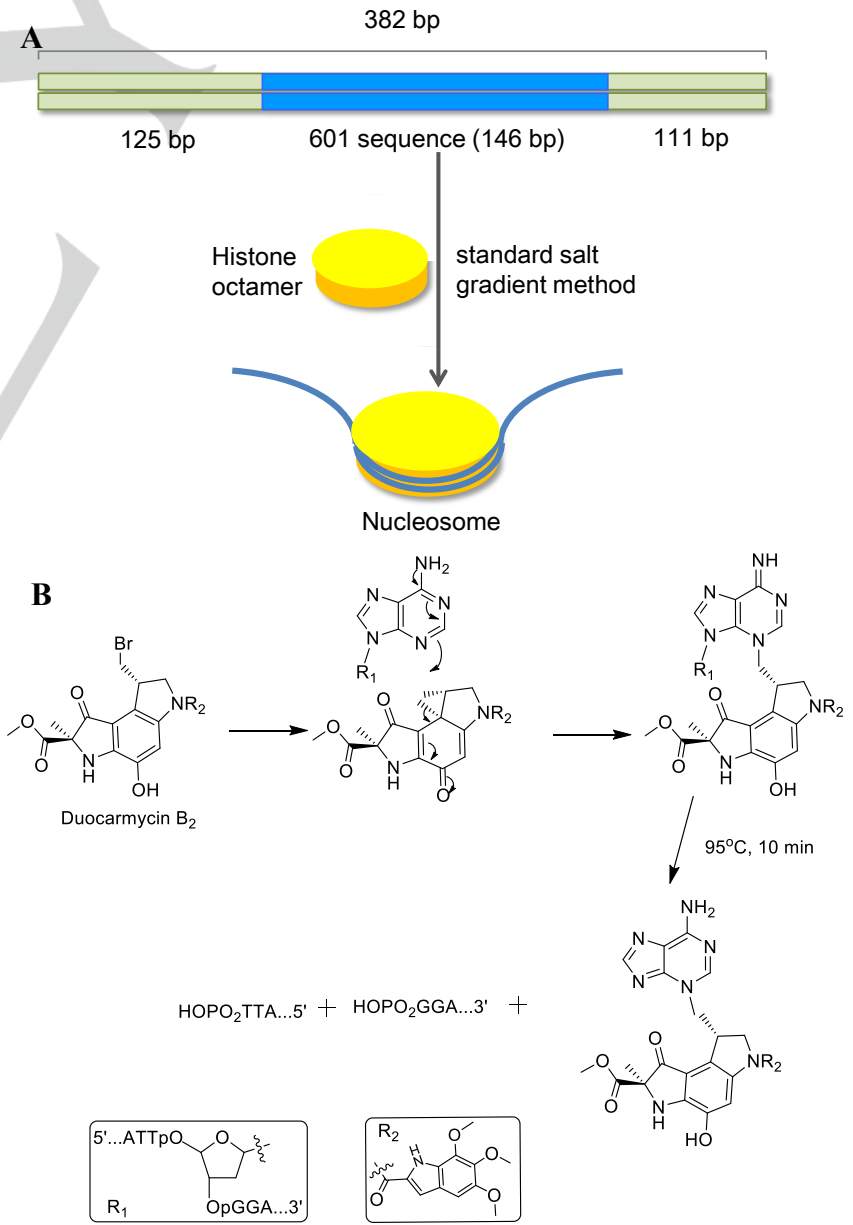

Figure 1. (A) Preparation of mono-nucleosome; (B) Mechanism of duocarmycin $\mathrm{B}_{2}$ alkylating DNA 
ACAGGATGTATATATCTGACACGTGCCTGGAACTAGGGAGTAATCCCCTTGGCGGTTAAAACGCGGGGGACAGCGCGTACGTGCGTTTÄGCGTGCTAGAGCTGTCTACGACC TGTCCTACATATATAGACTGTGCACGGACCTTGATCCCTCATTAGGGGAACCGCCAATTTTGCGCCCCCTGTCGCGCATGCACGCAAATTCGCCACGATCTCGACAGATGCTGG
site-3 $\downarrow$
site-4 $\downarrow$
site-5 $\downarrow \downarrow \quad$ Linker DNA
site-6 $\downarrow$

AATTGAGCGGCCTCGGCACCGGGATTCTCCAGGGCGGCCGCGTATAGGGTCCATCACATAAGGGATGAACTCGGTGGAAGAATCATGCTTTCCTTGGTCATTAGGATCCCGGAC TTAACTCGCCGGAGCCGTGGCCCTAAGAGGTCCCGCCGGCGCATATCCCAGGTAGTGTATTCCCTACTTGAGCCACCTTCTTAGTACGAAAGGAACCAGTAATCCTAGGGCCTG

CTGCAGGCATGCAAGCTTGAGTATTCTATAGTGTCACCTAAAT-3' GACGTCCGTACGTTCGAACTCATAAGATATCACAGTGGATTTA-5'

Purple major groove-inward regions Green minor groove-inward regions

Figure 2. The sequence of $382 \mathrm{bp}$ DNA and alkylating sites in core and linker DNA fragment.

and evaluation, to verify the influence of nucleosome assembly with linker part on the accessibility of small molecular agents into duplex DNA.

To construct the nucleosome structure, we used Texas red labeled 382 bp DNA containing 146 bp nucleosome-positioning 601 sequence $^{[16]}$ flanked by two DNA arms of different lengths, 125 and $111 \mathrm{bp}$, respectively (Figure 1A, Figure 2). Subsequently, we amplified DNA through PCR from pGEM3Z601 using the following primers: forward, 5'-Texas Red TAATACGACTCACTATAGG-3', and reverse, 5'ATTTAGGTGACACTATAGAATAC-3 $3^{\text {[17] }}$. After the reaction, the amplified DNA was purified using the GenElute PCR Clean-Up Kit (Sigma-Aldrich, St. Louis, MO, USA), The purified DNA was then used for nucleosome reconstitution with histone octamer (Epicypher, NC, USA) by standard salt gradient method ${ }^{[18][19]}$ The reconstitution efficiency was confirmed by gel mobility shift assay (6\% Native PAGE, 100V, 1h).

Duocarmycin $B_{2}$ at various concentrations with $6.25 \mathrm{mM}$ sodium phosphate buffer ( $\mathrm{pH} 7.0)$ alkylated the 5'-Texas Red labeled $382 \mathrm{bp}$ free-DNA or nucleosomes at room temperature for $18 \mathrm{~h}$. After incubation, the reaction mixture was quenched by addition of calf thymus DNA followed by heat treatment at $95^{\circ} \mathrm{C}$ for $10 \mathrm{~min}$. The alkylating mechanism of duocarmycin $B_{2}$ was showed in Figure 1B. The solution was concentrated using vacuum centrifugation. The pellet was re-dissolved in $7 \mu \mathrm{L}$ of loading dye, heated at $95^{\circ} \mathrm{C}$ for $25 \mathrm{~min}$, and then immediately cooled down to $0^{\circ} \mathrm{C}$. A $0.8 \mu \mathrm{L}$ aliquot was subjected to electrophoresis on a $6 \%$ denaturing polyacrylamide gel by using a Hitachi DNA sequencer ${ }^{[20]}$. The results were analyzed and shown with FRAGLYS version 2 in SSCP calculation mode.

The reconstituted nucleosomes confirmed by gel mobility shift assay (Figure $\mathrm{S} 1$ ) were directly used for alkylating reaction. After incubation at room temperature for $18 \mathrm{~h}$, gel shift was also used for confirming the nucleosome condition, in consistent with previous report ${ }^{[9]}$, the result (Figure S2) indicated that nucleosome dissociation was not caused by the treatment with agents, nucleosomes incubated at room temperature showed similar stability as incubated at $4^{\circ} \mathrm{C}$ for 18 hours. Because prolonging the cleaving time from $10 \mathrm{~min}$ to $50 \mathrm{~min}$ did not yield significant difference (Figure S3), heating at $95^{\circ} \mathrm{C}$ for 10 min was adopted in the subsequent investigations.

Varying concentrations of duocarmycin $B_{2}$ were tested in the presence of free-DNA or nucleosome in $20 \mathrm{nM}$ (Figure 3). In accordance with a previous report ${ }^{[9]}$, no unexpected alkylating sites were observed in either free DNA or nucleosomes. Both DNA and nucleosomes were alkylated to a higher degree with increasing concentrations of duocarmycin $\mathrm{B}_{2}$. Figure 2 indicates that, in the core DNA, all three alkylating sites located in the minor groove inward region, which is consistent with previous research. While evaluating the alkylating efficiency, while was we observed notable alkylating efficiency differences between nucleosome and free DNA samples. In the core DNA region, three alkylating sites were found which all showed an obvious decreasing alkylating efficiency for nucleosomes compared with free DNA, site 2 even exhibited a decrease in efficiency more than 3 fold (from $21.5 \%$ to $6.3 \%$ ) in the presence of $0.5 \mu \mathrm{M}$ duocarmycin $\mathrm{B}_{2}$ (Figures 3 and 4). However, the first site, which includes three possible alkylating adenines (Figure 2), sometimes shows fluctuating efficiency changes for predictable better agent accessibility.

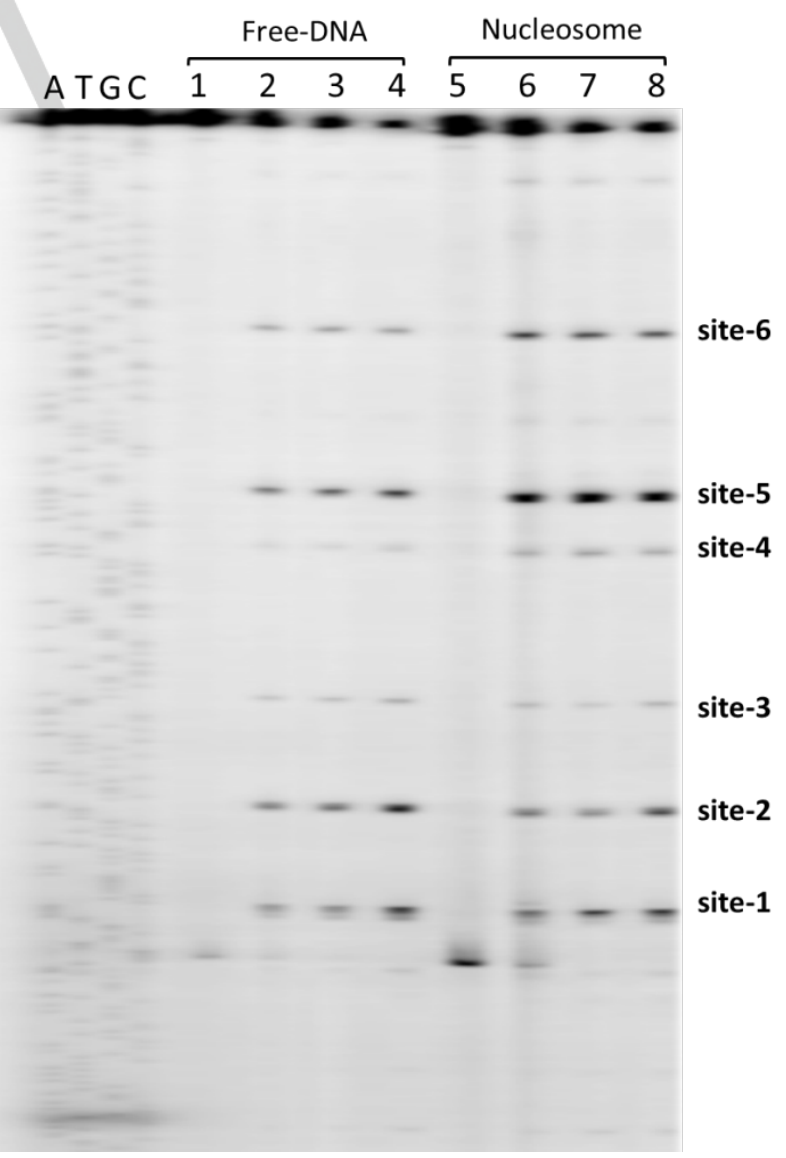

Figure 3. Thermally induced strand cleavage $\left(10 \mathrm{~min}, 95^{\circ} \mathrm{C}\right)$ of $382 \mathrm{bp}$ DNA and nucleosome with different concentration of duocarmycin $B_{2}$. lanes 1-4, free DNA (20 nM) + duocarmycin $\mathrm{B}_{2}(0.1 \mu \mathrm{M}, 0.25 \mu \mathrm{M}, 0.5 \mu \mathrm{M}$, respectively); lanes 5-8, nucleosome $(20 \mathrm{nM})+$ duocarmycin $\mathrm{B}_{2}(0.1 \mu \mathrm{M}$, $0.25 \mu \mathrm{M}, 0.5 \mu \mathrm{M}$, respectively). 


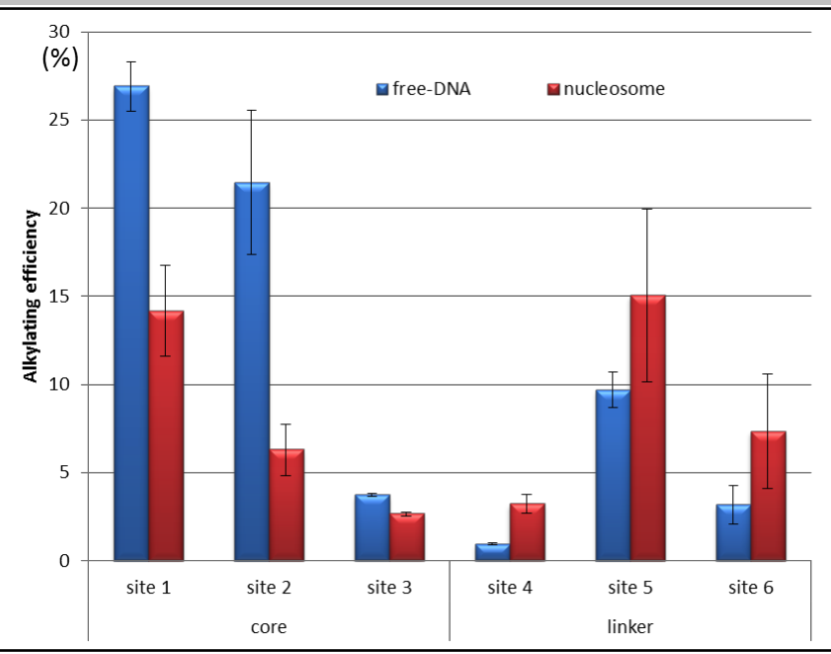

Figure 4. Alkylating efficacy of duocarmycin $B_{2}$ in $0.5 \mu \mathrm{M}$, with free DNA or nucleosome in $20 \mathrm{nM}$. The data are mean \pm SD of repeated experiments $(n=3)$.

In contrast with the decreasing alkylating efficacy observed at core sites, the efficiency of alkylating sites in the nucleosome linker DNA region was significantly increased when compared with that observed in the free DNA (Figure 3, Figure 4). Alkylating sites 5 on linker DNA region, which possesses a relatively higher reaction activity for two potential alkylating adenines, showed the most obvious alkylating band and efficiency increased from $9.7 \%$ to $15.0 \%$ in nucleosomal DNA. These results also suggest that, in the nucleosome structure, the linker DNA region shows similar or higher reactivity than the core DNA region. While in the naked DNA condition, lower reactivity in DNA linker region could be observed.

We also attempted to confirm these results using different concentrations of free DNA and nucleosome in the presence of $0.5 \mu \mathrm{M}$ duocarmycin $\mathrm{B}_{2}$, and similar tendencies were observed (Figure S4). These results indicated that the accessibility of duocarmycin $B_{2}$ to duplex DNA is altered in the presence of nucleosome assembly and the agent preferentially alkylates the naked DNA part (linker region) rather than the DNA that is packaged with histone proteins.

In conclusion, this present in vitro study was conducted to elucidate the mechanistic information regarding the accessibility of duocarmycin $\mathrm{B}_{2}$ to duplex DNA in nucleosomes containing a linker DNA region. Compared with free DNA, in the presence of nucleosome structure, duocarmycin $B_{2}$ showed a significantly decreased efficiency in accessing the nucleosome core DNA, while exhibiting an increased efficiency in accessing the linker DNA region. This finding also suggested that although the efficiency of alkylating agents enters into nucleosome core region showed decreased binding, the targeting capability is still retained, and even higher in linker DNA region, while might be considered when designing drugs for targeting key promoter region.

Keywords: Nucleosome • Duocarmycin $\mathrm{B}_{2} \cdot$ Alkylation • Accessibility

L. F. Tietze, F. Major, I. Schuberth, Angew. Chemie - Int. Ed. 2006, 45, 6574-6577.
[2] I. Takahashi, K. Takahashi, M. Ichimura, M. Morimoto, K. Asano, I. Kawamoto, F. Tomita, H. Nakano, J. Antibiot. 1988, 41, 1915-1917.

[3] T. Ogawa, M. Ichimura, S. Katsumata, M. Morimoto, K. Takahashi. J. antibiot. 1989, 8: 1299-1301.

[4] M. Tercel, G. J. Atwell, S. Yang, A. Ashoorzadeh, R. J. Stevenson, K. J. Botting, Y. Gu, S. Y. Mehta, W. A. Denny, W. R. Wilson, F. B. Pruijn, Angew. Chem. Int. Ed. 2011, 50, 2606-2609.

[5] D. L. Boger, T. Ishizaki, H. Zarrinmayeh, S. A. Munk, P. A. Kitos, O. Suntornwat, J. Am. Chem. Soc. 1990, 112, 89618971.

[6] H. Sugiyama, M. Hosoda, I. Saito, A. Asai, H. Saito, Tetrahedron Lett. 1990, 31, 7197-7200.

[7] S. Tan, C. A. Davey, Curr. Opin. Struct. Biol. 2011, 21, 128-136.

[8] J. M. Gottesfeld, C. Melander, R. K. Suto, H. Raviol, K. Luger, P. B. Dervan, J Mol Biol. 2001, 309, 615-629.

[9] J. D. Trzupek, J. M. Gottesfeld, D. L. Boger, Nat. Chem. Biol. 2006, 2, 79-82.

[10] G. E. Davey, B. Wu, Y. Dong, U. Surana, C. A. Davey, Nucleic Acids Res. 2009, 38, 2081-2088.

A. R. Cutter, J. J. Hayes, FEBS Lett. 2015, 589, 2914-2922. T. Ueda, H. Chou, T. Kawase, H. Shirakawa, M. Yoshida, Biochemsitry. 2004, 43, 9901-9908.

[13] A. M. Galea, V. Murray, Biochim. Biophys. Acta. 2002, 1579, 142-152.

[14] B. L. Smith, G. B. Bauer, L. E Povirk, J. Biol. Chem. 1994, 269, 30587-30594.

[15] M. T. Kuo, T. C. Hsu, Chromosoma (Bert.) 1978, 68, 229240.

[16] P. T. Lowary, J. Widom, J. Mol. Biol. 1998, 276, 19-42.

[17] S. Kizaki, Y. Suzuki, T. Takenaka, M. Endo, H. Sugiyama, Biomater. Sci. 2014, 2, 1399-1403.

[18] K. Luger, T. J. Rechsteiner, T. J. Richmond, Nature. 1999, 304, 1-19.

[19] Y.-W. Han, Y. Tsunaka, H. Yokota, T. Matsumoto, G. Kashiwazaki, H. Morinaga, K. Hashiya, T. Bando, H. Sugiyama, Y. Harada, Biomater. Sci. 2014, 2, 297-307.

[20] R. D. Taylor, Y. Kawamoto, K. Hashiya, T. Bando, H. Sugiyama, Chem. - An Asian J. 2014, 9, 2527-2533. 


\section{Entry for the Table of Contents}

\section{Layout 1:}

\section{COMMUNICATION}

\section{Nucleosome assembly influence:}

In vitro studies aimed at evaluating the alkylation level of duocarmycin $B_{2}$ on nucleosomes with core and linker DNA were conducted using sequencing gel electrophoresis. Our results suggested that in nucleosome structure, the alkylating efficiencies of duocarmycin $B_{2}$ were significantly decreased in core DNA and increased at the histone-free linker DNA sites compared with naked DNA condition.

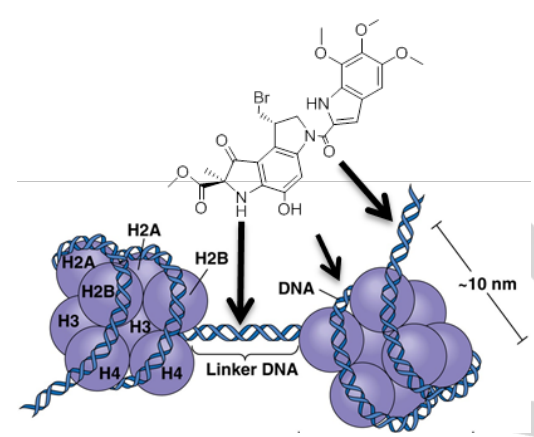

Tingting Zou ${ }^{a}$, Selichiro Kizaki $i^{a}$, Namasivayam Ganesh Pandian ${ }^{b}$, Hiroshi Sugiyama ${ }^{a}{ }^{b *}$

Page No. - Page No.

Nucleosome assembly alters the accessibility of the antitumor agent duocarmycin $B_{2}$ to duplex DNA 


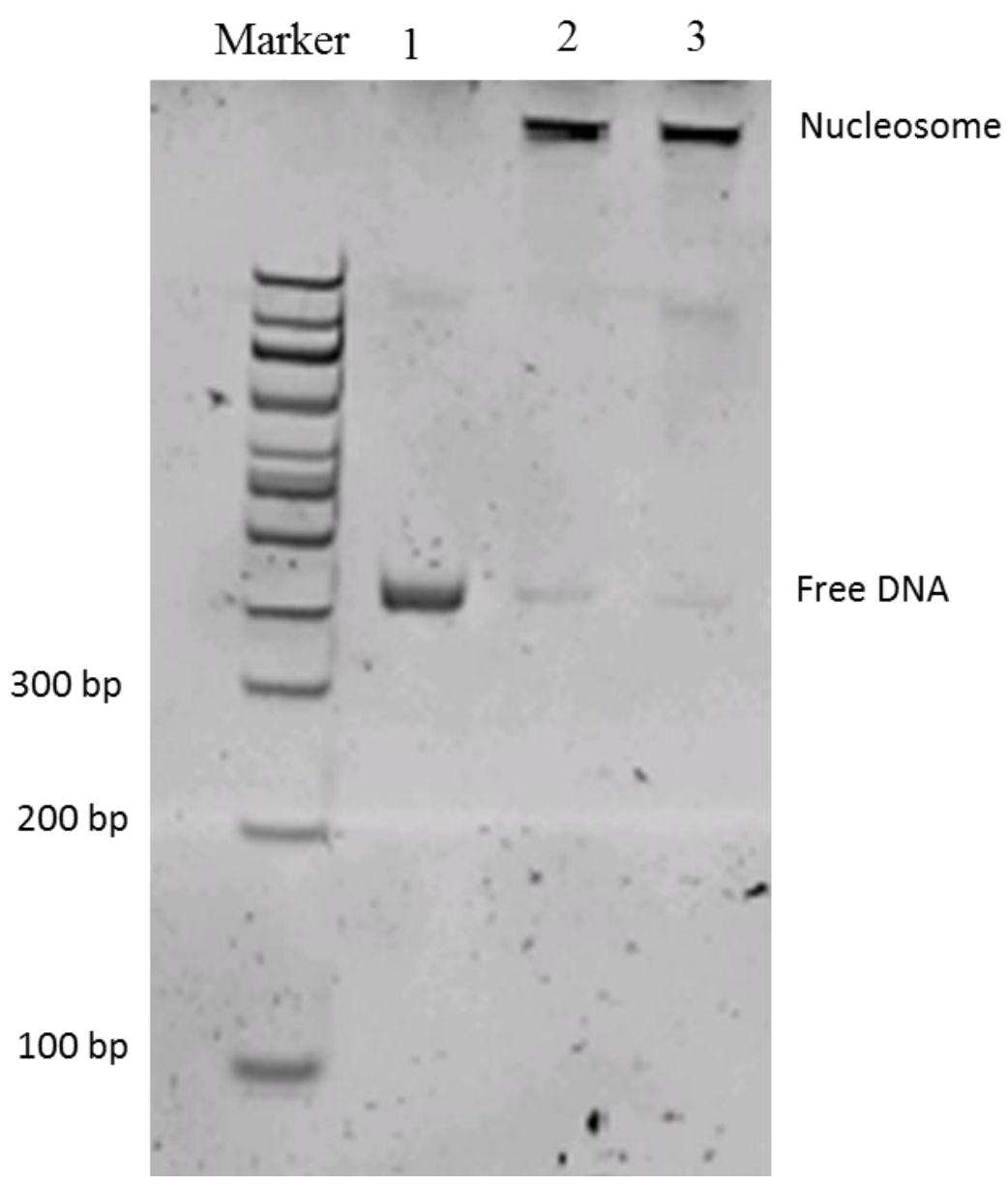

Figure S1. Nucleosome reconstitution efficiency confirmation, native gel electrophoresis of Texas red labeled 382 bp DNA and reconstituted nucleosomes (DNA: histone octamer in 2:3 molar ratio). Lane 1, control free DNA; lane 2, reconstituted nucleosome; lane 3, reconstituted nucleosome with unlabeled 382 bp DNA. 


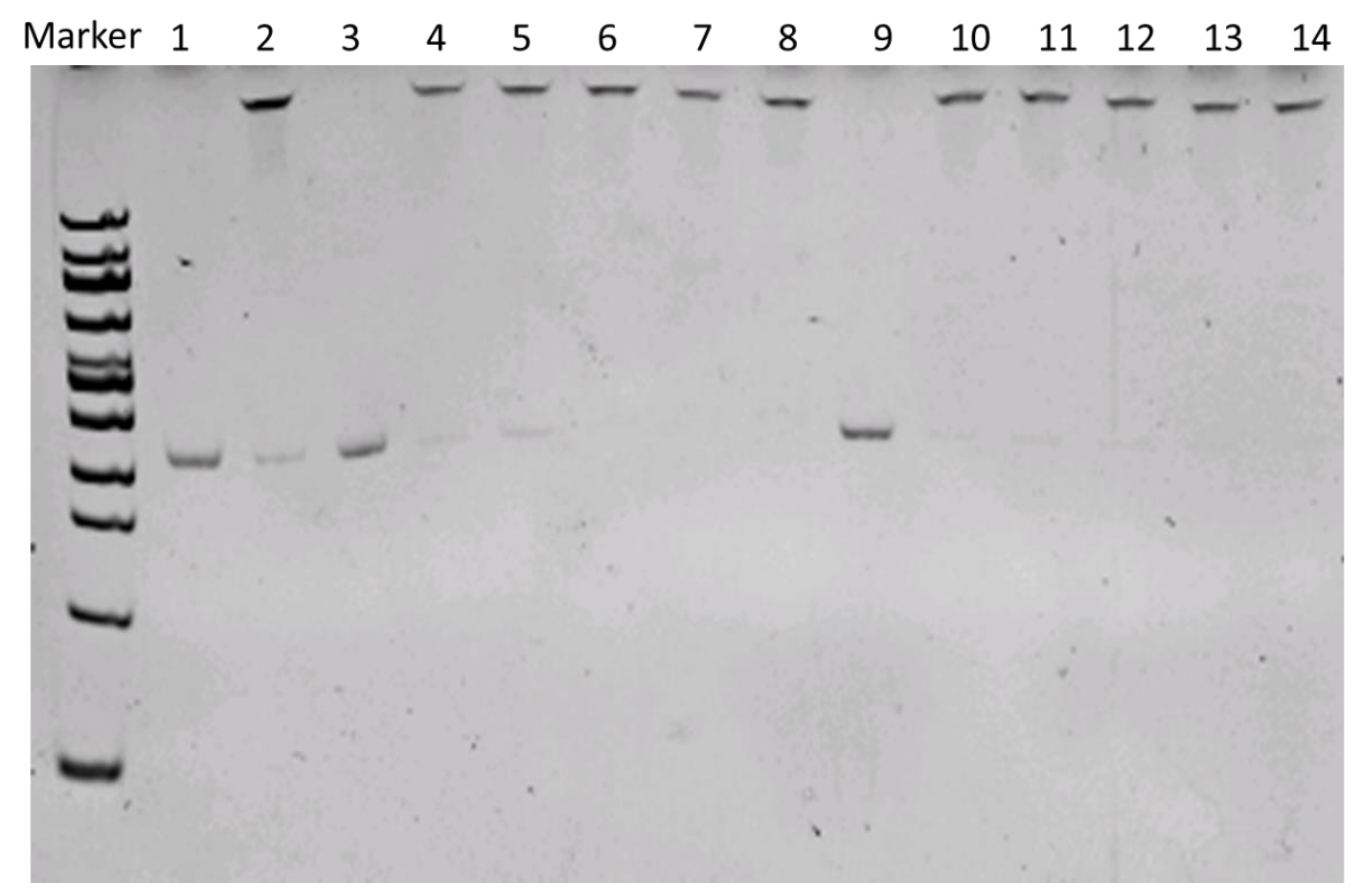

Figure S2. Nucleosome stability confirmation, non-denaturing gel electrophoresis of 5 ' end-Texas red labeled 601 DNA and reconstituted nucleosomes (DNA : histone octamer in 2:3). Lane 1, control free DNA; lane 2, reconstituted 601 nucleosome; lanes 3-8, room temperature, $18 \mathrm{~h}$, DNA or nucleosome in $20 \mathrm{nM}, 3$ : DNA with duocarmycin $(0.1 \mu \mathrm{M})$, 4: nucleosome control, 5-6: nucleosome with duocarmycin (0.1 $\mu \mathrm{M})$, 7-8: nucleosome with duocarmycin $(0.5 \mu \mathrm{M})$; lanes $9-14,4^{\circ} \mathrm{C}, 18 \mathrm{~h}, 9$ : DNA with duocarmycin $(0.1$ $\mu \mathrm{M}), 10$ : nucleosome control, 11-12: nucleosome with duocarmycin $(0.1 \mu \mathrm{M}), 13-14$ : nucleosome with duocarmycin $(0.5 \mu \mathrm{M})$. 


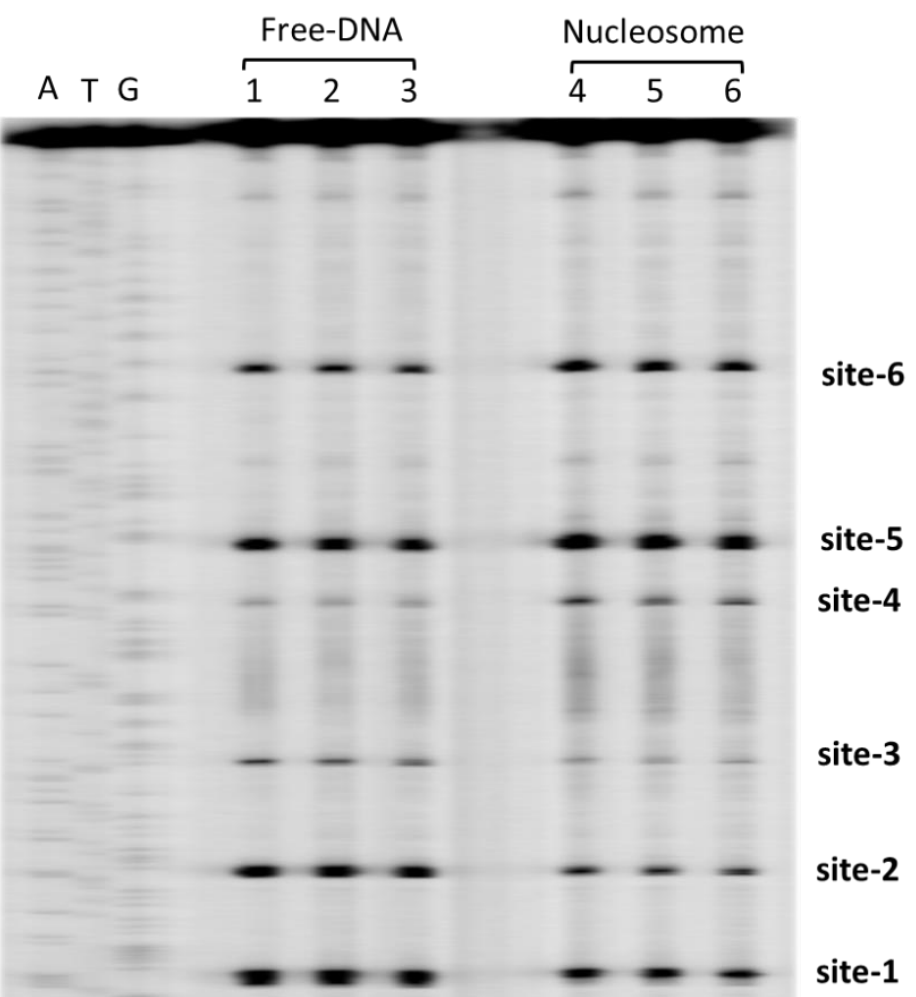

Figure S3. Thermally induced strand cleavage of $382 \mathrm{bp}$ DNA and nucleosome with different heating time. Lanes 1-3, free DNA (30 nM ) + duocarmycin $B_{2}(0.5 \mu \mathrm{M})$, heating in $95^{\circ} \mathrm{C}(10 \mathrm{~min}, 25 \mathrm{~min}, 50$ min, respectively) ; lane 4-6, nucleosome $(30 \mathrm{nM})+$ duocarmycin $\mathrm{B}_{2}(0.5 \mu \mathrm{M})$, heating in $95^{\circ} \mathrm{C}(10$ $\min , 25 \mathrm{~min}, 50 \mathrm{~min}$, respectively). 


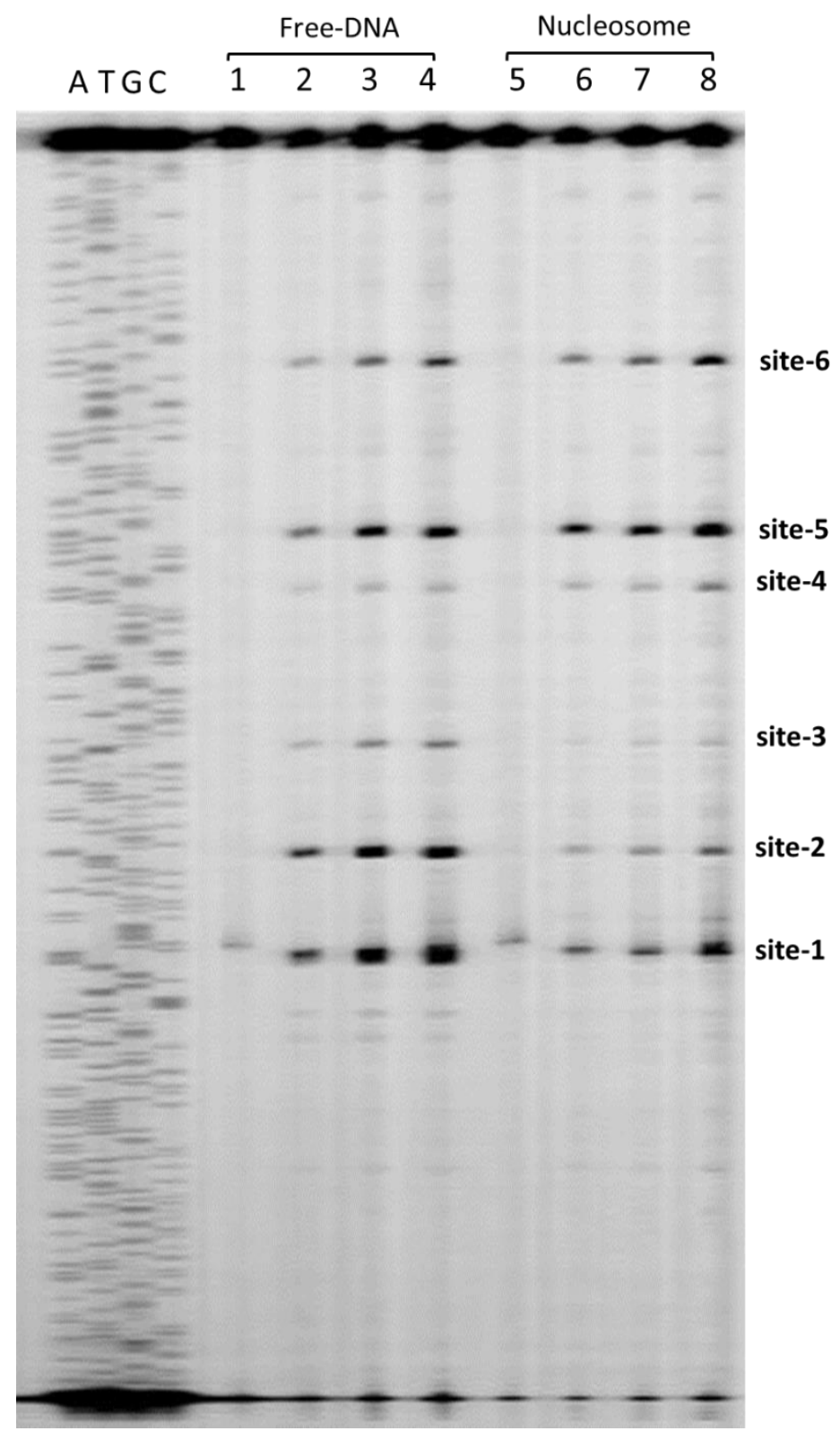

Figure S4. Thermally induced strand cleavage $\left(10 \mathrm{~min}, 95^{\circ} \mathrm{C}\right)$. lane 1 , control free DNA; lanes 2-4, duocarmycin $\mathrm{B}_{2}(0.5 \mu \mathrm{M})+$ free DNA $(10 \mathrm{nM}, 20 \mathrm{nM}$ and $30 \mathrm{nM}$ respectively); lane 5, control nucleosome; lanes 6-8, duocarmycin $B_{2}(0.5 \mu M)+$ nucleosome $(10 \mathrm{nM}, 20 \mathrm{nM}$ and $30 \mathrm{nM}$, respectively). 